\title{
Guidelines on the use of fluoride for caries prevention in children: an updated EAPD policy document
}

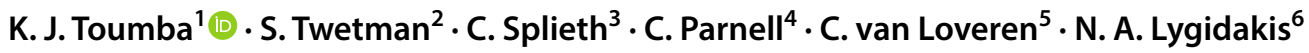

Received: 10 June 2019 / Accepted: 21 June 2019 / Published online: 8 November 2019

(c) The Author(s) 2019

\begin{abstract}
Aim To update the exisitng European Academy of Paediatric Dentistry (EAPD) 2009 fluoride guidelines.

Methods Experts met in Athens, Greece duirng November 2018 for the following groups: I Fluoride toothpastes, II Fluoride gels, rinses and varnishes, III Fluoridated milk, fluoridated salt, tablets/lozenges and drops, IV Water fluoridation. Systematic reviews and meta-analyses were reviewed and discussed for each of the groups. The GRADE system was used to assess the quality of evidence which was judged as HIGH, MODERATE, LOW or VERY LOW based on the assessment of eight criteria which can influence the confidence of the results. Following the quality assessment, GRADE was then used to indicate the strength of recommendation for each fluoride agent as STRONG or WEAK/CONDITIONAL.

Results Parents must be strongly advised to apply an age-related amount of toothpaste and assist/supervise tooth brushing until at least 7 years of age. The EAPD strongly endorses the daily use of fluoride as a major part of any comprehensive programme for the prevention and control of dental caries in children. Regardless of the type of programme, community or individually based, the use of fluoride must be balanced between the estimation of caries-risk and the possible risks of adverse effects of the fluorides. Fluoride use is considered safe when the manufacturer's instructions are followed. Preventive programmes should be re-evaluated at regular intervals and adapted to a patient's or population's needs and risks.

Conclusions For the majority of European Countries, the EAPD recommends the appropriate use of fluoride toothpaste in conjunction with good oral hygiene to be the basic fluoride regimen.
\end{abstract}

Keywords Fluoride $\cdot$ Caries $\cdot$ Child

\section{Background considerations}

The European Academy of Paediatric Dentistry (EAPD), in collaboration with the Hellenic Division of EAPD, organ-

K. J. Toumba

jack.toumba@hsc.edu.kw

1 Developmental and Preventive Sciences, Faculty of Dentistry, Kuwait University, Kuwait city, Kuwait

2 Department of Odontology, Faculty of Health and Medical Sciences, University of Copenhagen, Copenhagen, Denmark

3 Department of Preventive and Paediatric Dentistry, University of Greifswald, Greifswald, Germany

4 Oral Health Services Research Centre and HSE, Louth, Meath, Ireland

5 Department of Cariology, Academic Centre for Dentistry (ACTA), University of Amsterdam, Amsterdam, The Netherlands

6 Private Paediatric Dental Clinic, 2 Papadiamantopoulou Street, 11528 Athens, Greece ised a workshop in Athens, Greece (June 1997), aimed at drawing up guidelines for future use of fluorides among European children. The first draft of these guidelines was published in the EAPD newsletter, and members were invited to make comments and suggestions. The revised first draft was then presented at the biannual EAPD Congress in Sardinia (1998), where it was discussed in great detail, so that the members' viewpoints were taken into consideration. The major concepts of the proposed guidelines were approved, and a working group, consisting of the authors of the original paper, were authorised to finalise and publish the recommendations (Oulis et al. 2000). In November 2008, the EAPD organised another workshop, again in Athens, Greece, to update the original fluoride guidelines (Toumba et al. 2009). These updated fluoride guidelines employed the 
evidence-based SIGN (Scottish Intercollegiate Guidelines Network) methodology for ranking the levels of evidence and the grades of recommendations (SIGN 83 2005; SIGN 50 2008). In November 2018, the EAPD organised another workshop, once again in Athens, Greece, to update the fluoride guidelines. These updated fluoride guidelines employed the GRADE system (Ryan and Hill 2016) to assess the quality of evidence for the caries-preventive effect of various topical and systemic fluoride agents. The quality of evidence was judged as HIGH, MODERATE, LOW or VERY LOW, based on the assessment of eight criteria which can influence our confidence in the results (Marinho et al. 2011). These criteria are: risk of bias, indirectness, inconsistency, imprecision, publication bias, a large magnitude of effect, dose response and the effect of all plausible confounding factors for reducing the effect or suggesting a spurious effect. Following the quality assessment, GRADE was then used to indicate the strength of recommendation for each fluoride agent as STRONG or WEAK/CONDITIONAL. The interpretation of the gradings for quality of evidence and strength of recommendation are shown in Tables 1 and 2.

\section{Introduction}

Fluorides are the key element to successful caries prevention (Marinho 2009; O’Mullane et al. 2016). They are also effective as therapeutic agents in non-restorative caries treatment (NRCT) for the inactivation or arrest of caries lesions
(Slayton et al. 2018; Urquhart et al. 2019), but the present EAPD guidelines focus on their preventive effect only.

Evidence suggests that the cariostatic effect of fluoride is mostly exerted by its topical rather than systemic effect (Featherstone 1999). This effect might be even greater when combined with good oral hygiene, such as when practiced as comprehensive tooth brushing with a fluoride toothpaste (Rolla et al. 1991).

Concern about the prevalence of dental fluorosis in some children has mostly been related to the use of fluoride supplements, especially during the first 6 years of life (Ismail and Bandekar 1999). However, it has also been shown that early exposure to fluoride toothpaste might also be a risk factor due to the unintended ingestion of toothpaste (Levy et al. 1995; Wong et al. 2010). Studies that have summarised the risks for dental fluorosis have concluded that the risk is highest when the exposure takes place in both the secretory and the maturation phases of enamel formation (DenBesten 1999; Wong et al. 2010). Therefore, three age groups can be considered in terms of having a risk for enamel fluorosis, namely:

\section{0-4 years}

Babies and children under the age of 4 years are considered to be at risk of dental fluorosis of permanent incisors and first molars, because the calcification and maturation of these teeth occur during this period of life. The longitudinal Iowa study found that exposure to fluoride during the first

Table 1 GRADE ratings and their interpretation

\begin{tabular}{|c|c|}
\hline $\begin{array}{l}\text { GRADES } \\
\text { of evidence } \\
\text { quality }\end{array}$ & Interpretation \\
\hline HIGH & We are very confident that the true effect lies close to that of the estimate of the effect \\
\hline MODERATE & $\begin{array}{l}\text { We are moderately confident in the effect estimate: the true effect is likely to be close to the estimate of the effect, but there is a } \\
\text { possibility that it is substantially different }\end{array}$ \\
\hline LOW & Our confidence in the effect estimate is limited: the true effect may be substantially different from the estimate of the effect \\
\hline VERY LOW & $\begin{array}{l}\text { We have very little confidence in the effect estimate: the true effect is likely to be substantially different from the estimate of } \\
\text { effect }\end{array}$ \\
\hline
\end{tabular}

Table from the GRADE Handbook, available at http://gdt.guidelinedevelopment.org/app/handbook/handbook.html\#h.9rdbelsnu4iy

Table 2 Strengths of recommendation for patients, clinicians and policy makers Adapted from Guyatt et al. (2008)

\begin{tabular}{lll}
\hline & Strong recommendation & Conditional recommendation \\
\hline For patients & $\begin{array}{c}\text { Most people would want the recommended course of action } \\
\text { and only a small proportion would not }\end{array}$ & $\begin{array}{c}\text { Most people would want the recommended course of action, } \\
\text { but many would not }\end{array}$ \\
For clinicians & $\begin{array}{c}\text { Mostients should receive the recommended course of } \\
\text { action }\end{array}$ & $\begin{array}{c}\text { Different choices will be appropriate for different patients and } \\
\text { each patient should be advised for a management decision } \\
\text { consistent with her/his values and preferences }\end{array}$ \\
For policy makers & $\begin{array}{c}\text { The recommendation can be adopted as a policy in most } \\
\text { situations }\end{array}$ & $\begin{array}{c}\text { Policy making will require substantial debate and involvement } \\
\text { of stakeholders }\end{array}$ \\
\hline
\end{tabular}


3 years of life were most important for fluorosis development on the permanent maxillary incisors, but other individual periods were also important (Hong et al. 2006). It is during this period when the use of fluorides must be carefully monitored and balanced with the need to prevent the occurrence of early childhood caries. Special attention should be given to the use of topically applied fluorides during this period of life, because of the inadequate control of the swallowing reflex.

\section{4-6 years}

The posterior teeth (premolars and second molars) are calcifying and maturing during this period and at risk of dental fluorosis. Nevertheless, when this occurs, it represents less of an aesthetic problem, which needs to be weighed against the marked benefit of caries prevention brought about by the use of fluoride.

\section{6 years and above}

The risk for enamel fluorosis during this period is negligible, except for third molars.

\section{Use of silver diamine fluoride}

Silver diamine fluoride (SDF) at a concentration of $38 \%$ $(44,800 \mathrm{ppmF})$ has been rarely used in Europe to arrest or prevent dental caries, whereas in the Americas, Australasia and Asia, it has been frequently used to arrest dental caries in children (Gao et al. 2019; Tiripathi et al. 2019). The American Academy of Pediatric Dentistry (AAPD) produced guidelines (Crystal et al. 2017) on the use of SDF for the management of dental caries in children based on a systematic review of Gao et al. (2016). Per GRADE, this is a CONDITIONAL recommendation based on low-quality evidence. Interest in the use of SDF in Europe is now growing.

\section{Guidelines}

The following guidelines are recommended as an integral part of preventive programmes for children. It must be emphasised, however, that any dentist supervising a child's oral care must address individual needs.

\section{Fluoride toothpastes}

\section{Clinical effectiveness}

The widespread use of fluoride toothpastes has most likely been one of the major reasons for the reduction of dental
Table 3 Caries-preventive effect of fluoride toothpaste

\begin{tabular}{llc}
\hline Intervention & Control & PF \% (95\% CI) \\
\hline Fluoride toothpaste & Placebo & $24(21-28)$ \\
Supervised brushing & Non-supervised & $11(4-18)$ \\
Brushing twice per day & Once per day & $14(6-22)$ \\
$1450-1500$ ppm F & $1000-1100$ ppm F & $8(1-16)$ \\
$\begin{array}{l}\text { Fluoride toothpaste +other } \\
\text { sources* }\end{array}$ & Fluoride toothpaste & $10(2-17)$ \\
\hline
\end{tabular}

PF is prevented fraction, expressed as percentage, with confidence intervals (Marinho 2009)

*Water fluoridation, fluoride varnish, fluoride gel, or fluoride mouth rinsing

caries recorded over the past 40 years. Tooth brushing with fluoride toothpaste is close to an ideal public health method being convenient, inexpensive, culturally approved and widespread (Burt 2008). The use of fluoride toothpaste in children and adolescents has been subjected to several systematic reviews (Marinho et al. 2003; Twetman et al. 2003; Twetman 2009; Wong et al. 2011; Wright et al. 2014; Walsh et al. 2019) and all have confirmed its efficacy in preventing caries. The magnitude, expressed as caries prevented fraction (PF), is summarised in Table 3.

\section{Potential harm}

One problem with young children's use of toothpaste is that they swallow some paste with a subsequent risk of fluorosis (Wong et al. 2011). Fluoride toothpaste may be responsible for up to $80 \%$ of the "optimal" total daily intake of fluoride (Mejare 2018) and the first 3 years of life seems most critical. Therefore, parents must be strongly advised to apply an age-related amount of toothpaste and assist/supervise tooth brushing until at least 7 years of age. To support parents and caregivers to apply the right amount of toothpaste (grain of rice or pea size), manufacturers, public health institutions and national societies are encouraged to provide clear visual instructions on toothpaste packaging and in brushing instructions. Toothpaste with a lower concentration than $1000 \mathrm{ppm}$ can be considered for young children regularly exposed to other sources of fluoride. However, the evidence for these low fluoride concentration toothpastes of less than $1000 \mathrm{ppm}$ for the prevention of dental caries is limited (Walsh et al. 2019).

\section{Evidence-based statements}

Based on systematic reviews with moderate or low risk of bias, the following statements can be formulated (Table 4). 
Table 4 Statements with quality of evidence and strength of recommendation according to GRADE

\begin{tabular}{lll}
\hline Statement & $\begin{array}{l}\text { GRADE of evi- } \\
\text { dence quality }\end{array}$ & $\begin{array}{l}\text { GRADE of } \\
\text { recommendation } \\
\text { strength }\end{array}$ \\
\hline $\begin{array}{l}\text { Daily brushing with fluoride toothpaste prevents caries } \\
\begin{array}{l}\text { Toothpastes containing higher concentrations of fluoride are more } \\
\text { effective than those with lower concentration in preventing caries }\end{array}\end{array}$ & High & Strong \\
$\begin{array}{l}\text { Supervised tooth brushing is more effective than non-supervised } \\
\begin{array}{l}\text { There is inconclusive evidence that the use of fluoridated tooth- } \\
\text { paste in young children is associated with an increased risk of } \\
\text { fluorosis }\end{array}\end{array}$ & High & Low \\
\hline
\end{tabular}

Table 5 Recommended use of fluoride toothpastes in children

\begin{tabular}{lclll}
\hline Age (years) & $(\mathrm{ppm}$ F) & Frequency & Amount $(\mathrm{g})$ & Size \\
\hline $\begin{array}{l}\text { First tooth- } \\
\text { up to }\end{array}$ & 1000 & Twice daily & 0.125 & Grain of rice \\
2 years & & & & \\
2-6 years & $1000^{*}$ & Twice daily & 0.25 & Pea \\
Over 6 years & 1450 & Twice daily & $0.5-1.0$ & $\begin{array}{c}\text { Up to full } \\
\text { length of } \\
\text { brush }\end{array}$ \\
& & & &
\end{tabular}

*For children 2-6 years, 1000+ fluoride concentrations may be considered based on the individual caries risk

\section{Good practice points on brushing behaviour}

There are common recommendations on brushing behaviour that are based on expert opinions and consensus rather than on firm evidence:

- Tooth brushing should be conducted so each tooth surface is reached and brushing should exceed $1 \mathrm{~min}$, also in preschool children.

- Children should avoid rinsing with a lot of water afterwards.

- Children's teeth should be brushed using either a soft manual or power toothbrush.

\section{High fluoride toothpaste}

Toothpastes with more than $1500 \mathrm{ppm} \mathrm{F}$ are available on prescription in many countries. Toothpastes containing up to 5000 ppm $\mathrm{F}$ are primarily intended for patients with special care needs, adolescents with increased caries risk and those under treatment with fixed orthodontic appliances. Conclusive evidence for their superior effectiveness is, however, lacking (Pretty 2016).

\section{Clinical recommendations}

The EAPD recommendations for the use of fluoride toothpastes in children are summarised in Table 5.
Twice daily use of fluoride toothpaste, in combination with oral hygiene instructions, is the cornerstone of any preventive programme for children, irrespective of caries risk. Although the caries-preventive effect is statistically significant only for concentrations of $1000 \mathrm{ppm}$ and above, toothpastes with lower concentrations may have some beneficial effects and could be considered for children at low caries risk where the risk of fluorosis is of concern (Wong et al. 2011). The evidence of efficacy for outreach supervised fluoride tooth brushing programmes targeting low socioeconomic high-risk groups and ethnic minorities remains low (da Silva et al. 2016; Dos Santos et al. 2018). Where fluoride is used in conjunction with other fluoride vehicles, the cumulative fluoride exposure must be taken into consideration for children less than 6 years of age. Care must be taken to ensure that a balance between maximising the preventive effect against dental caries and minimising the risk of dental fluorosis is maintained. Furthermore, best available scientific evidence must be balanced with the expertise of dental professionals and the families' expectations and preferences. The background fluoride exposure as well as the socio-economic level of the community may also influence the abovementioned recommendations.

\section{Knowledge gaps}

According to a map of systematic reviews in paediatric dentistry (Mejàre et al. 2015), further research is needed on

- The appropriate amount and concentration of fluoride in toothpastes for preschool children related to the risk of fluorosis.

- The effect of toothpaste introduction age, optimal brushing time and post-brushing behaviour on caries development.

\section{Fluoride gels, rinses and varnishes}

Apart from the basic caries prevention by the use of fluoridated toothpaste, other topical fluorides can be used especially in children assessed as being at increased risk for 
caries development, including children with special oral health care needs or under orthodontic treatment and in risk periods such as tooth eruption. The evidence for the caries-preventive effect of gels, rinses and varnishes is greater in quality and quantity for permanent than primary teeth (Marinho et al. 2013, 2015, 2016; Twetman and Keller 2016). Especially in preschool children, the risk of ingestion and subsequent dental fluorosis should be weighed against the potential caries-preventive benefits. Additionally, the cost effectiveness has to be considered for groups with low caries prevalence (Schwendicke et al. 2018). This is also true for the mode of application, e.g., with gels, where in-office application offers greater control, but also higher costs, compared with settings such as schools or home application with lower costs, but also possibly reduced compliance.

\section{Clinical recommendations}

Available evidence, recommendations and good practice points for fluoride gels, rinses and varnishes in children and adolescents are shown in Table 6.

\section{Fluoridated milk, fluoridated salt, fluoride tablets/lozenges and drops}

\section{Fluoridated milk}

Milk fluoridation has been reported to be successful in dental caries prevention, particularly among children, and schemes have been developed in countries around the globe based on integration with school health and nutrition programmes (Jürgensen and Petersen 2013). Fluoridated milk is only ingested by children on school days and therefore not at weekends and school holidays. As no effort is required from the individual for ingesting fluoridated water, salt or milk, these methods have been designated as automatic systems for dental caries prevention. The use of milk as a vehicle for providing additional fluoride in dental public health programmes was evaluated in two recent systematic reviews (Cagetti et al. 2013; Yeung et al. 2015). Cagetti et al. (2013) searched literature from 01.01.1966 to 03.31.2011 and found nine papers of which only two papers fulfilled their inclusion criteria (Bian et al. 2003; Stecksén-Blicks et al. 2009). Both these studies investigated the caries-prevention effect of milk fluoridation on primary teeth. In the first study, the GRADE recommendation strength is CONDITIONAL (Bian et al. 2003), each participant consumed $200 \mathrm{ml}$ of fluoridated milk (concentration $2.5 \mathrm{mg}$ F-per litre) a day for 21 months. At the end of the experimental period, the mean net caries increment was $0.4 \mathrm{dmft}$ for the test group and 1.3 $\mathrm{dmft}$ for the control group ( $t$ test, $p<0.001$ ). The second study (Stecksén-Blicks et al. 2009) evaluated the effect of fluoridated milk on caries development in preschool children. Children in the intervention group received $150 \mathrm{ml}$ of milk supplemented with $2.5 \mathrm{mg}$ of fluoride per litre for lunch, while the control group received standard milk for 21 months. The authors concluded that daily consumption of milk containing fluoride reduced caries in preschool children, with a prevented fraction of $75 \%$. The GRADE strength of recommendation for this study was also CONDITIONAL. Of the other five studies, only one study (Ketley et al. 2003) failed to demonstrate the caries-preventive effect of milk fluoridation. Four studies suggested that fluoridated milk had a beneficial effect, reducing caries incidence in both the primary and permanent dentitions. Cagetti et al. (2013) concluded that the consumption of fluoridated milk was an effective measure to prevent caries in primary teeth but that there was low evidence that the use of milk fluoridation was effective in reducing the caries increment.

Yeung et al. (2015) included in a Cochrane review only one unpublished RCT and concluded that there was lowquality evidence to suggest that fluoridated milk may be beneficial to schoolchildren, contributing to a substantial reduction in dental caries in primary teeth. Due to the low quality of the evidence, further research is likely to have an important impact on our confidence in the estimate of effect. Furthermore, there was no information about the potential adverse effects of the intervention. Additional RCTs of high quality are needed before we can draw definitive conclusions about the benefits of milk fluoridation (Yeung et al. 2015).

\section{Fluoridated salt}

Traditionally, the fluoridation of salt has been considered as an effective method for reducing caries, especially in areas where water fluoridation cannot be implemented. Two systematic reviews have been published on the clinical effectiveness of salt fluoridation (Yengopal et al. 2010; Cagetti et al. 2013). In one of these (Cagetti et al. 2013), no paper related to the use of salt fluoridation in caries prevention fulfilled the inclusion criteria, and the other one (Yengopal et al. 2010) concluded that the contribution of fluoridated salt to the decrease in the prevalence of caries could not be quantified, and further high-quality studies are needed. Wennhall et al. (2014) observed that domestic salt in low caries communities with vulnerable groups of schoolchildren did not seem to reduce the number of new caries lesions or slow down the progression rate. But, it should be taken into account that several confounders and bias were identified in this study.

Fabruccini et al. (2016) concluded that in a cross-sectional oral health survey, fluoridated water appeared to provide a better protective effect against caries than fluoridated salt among schoolchildren from developing countries. However, Jordan et al. (2017) observed that the use of fluoridated 


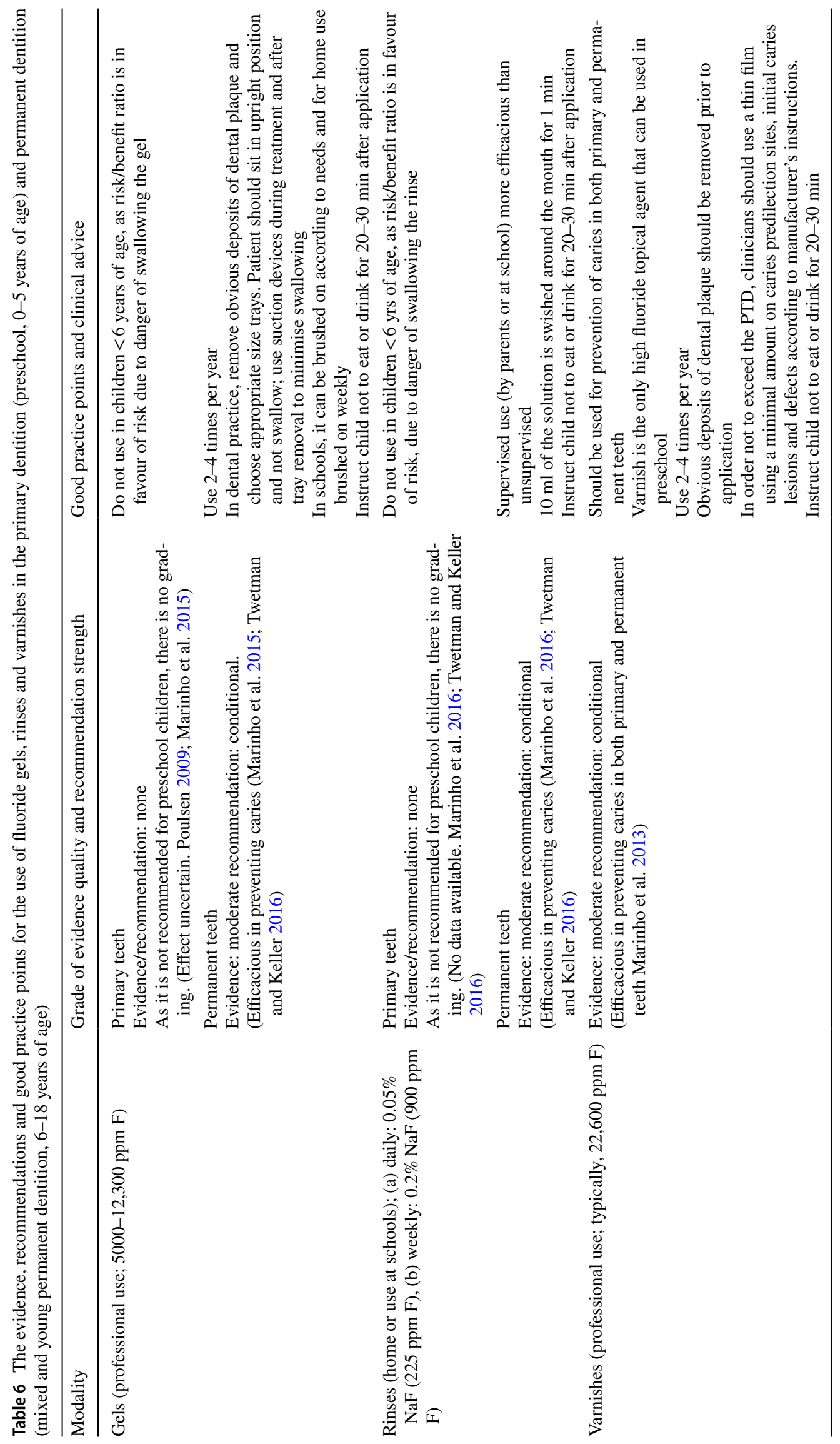


salt in a community feeding programme in an environment with negligible availability of fluoride from other sources resulted in a considerable caries-preventive effect.

Salt fluoridation is suggested (Pollick 2013; O'Mullane et al. 2016) when water fluoridation cannot be implemented, but one concern is that promotion of salt consumption for oral health benefits would be contradictory to the desired reduction of consumption of salt to decrease the risk of hypertension, and the drawbacks related to variation in ingestion resulted in difficulties in maintaining an ideal concentration.

\section{Fluoride tablets/lozenges and drops}

Fluoride tablets/lozenges and drops were first introduced to provide systemic fluoride in areas where water fluoridation was not available. At the time of introduction, the effectiveness of fluoride toothpaste was not yet firmly established. Since the mid 1970s, effective fluoride toothpastes became widely available. In these years, it was also accepted that the post-eruptive effects of fluorides were sufficiently strong to keep one's teeth healthy when properly used (Fejerskov et al. 1981; Fejerskov 2004). These findings rated fluoride tablets/lozenges and drops as less meaningful caries-preventive measures. Additionally, when using them, care should be taken that the products have sufficient substantivity in the oral cavity to also exert a topical effect.

In 2009, the EAPD concluded that at that time there was a lack of evidence to make good recommendations (Swedish Council on Technology Assessment in Health Care 2002; Espelid 2008). The EAPD also advised to monitor the total daily amount of fluoride ingested which should not exceed $0.07 \mathrm{mg} / \mathrm{kg}$ bodyweight daily (Fejerskov et al. 1977).

Since the previous position paper of the EAPD et al. (2009), no new RCTs examining the effect of fluoride tablets/lozenges or drops have been published. Two systematic reviews concluded that there might be an effect for permanent dentition, but that there was no clarity on the effect on primary dentition (Tubert-Jeanin et al. 2011; Tomasin et al. 2015). It has to be noted that both reviews examined older studies, conducted at a time when topical fluorides were not widely used and that were also available when the previous position paper of the EAPD (2009) was compiled.

One Cochrane review examining whether it was beneficial for pregnant women to use fluoride supplements to prevent future dental caries in their offspring found no evidence to support this (Takahashi et al. 2017).

\section{Recommendation}

Fluoridated milk and fluoridated salt could be part of community health programmes in target groups with high caries prevalence and low compliance for tooth brushing with fluoridated toothpaste in areas without water fluoridation (GRADE of recommendation: CONDITIONAL). Fluoride tablets/lozenges and drops could be considered on an individual basis for children at high risk for caries (GRADE of recommendation: CONDITIONAL), but improving the quality of tooth brushing or using a higher concentration of fluoridated toothpaste would be the first option.

\section{Water fluoridation}

\section{Water fluoridation}

In the 21st century, dental caries remains a global health problem. It is estimated that 573 million children worldwide have untreated dental caries in their primary teeth, while untreated caries in permanent teeth affects 2.5 billion people (Kassebaum et al. 2017). Community water fluoridation (CWF) is the process of adjusting the amount of fluoride found in water to achieve optimal prevention of dental caries (Centers for Disease Control and Prevention 2016). The fluoride concentration of water in CWF programmes typically ranges from 0.5 to $1.1 \mathrm{mg} / \mathrm{L}$.

CWF was introduced over 70 years ago as a public health measure to prevent and control caries at a population level, and in many countries throughout the world, CWF remains a core component of oral health policy. In 2012, the worldwide total of people supplied with artificially fluoridated water was estimated at approximately 370 million (British Fluoridation Society 2012).

The great advantage of CWF is that it benefits all residents in a community, regardless of age, socio-economic status, education, oral hygiene practices, employment or access to routine dental care, making it a truly equitable public health practice (Buzalaf et al. 2011; Public Health Agency of Canada 2016). CWF is also a cost-effective method of delivering caries prevention to a large population, and the larger the community served is, the greater the cost saving will be (Ran and Chattopadhyay 2016).

The effectiveness of CWF at preventing dental caries has been extensively and regularly investigated since the middle of the 20th century. A recent Cochrane review estimated that the initiation of CWF reduced caries levels by $35 \%$ in the primary dentition and $26 \%$ in the permanent dentition of children. The review also found that CWF led to a $15 \%$ increase in the percentage of children with caries-free primary teeth and a $14 \%$ increase in the percentage of children with caries-free permanent dentitions, compared to children without water fluoridation (Iheozor-Ejiofor et al. 2015). The reviewers questioned the applicability of these results to current lifestyles, as most of the included studies were conducted before the widespread use of fluoride toothpaste. The inclusion criteria of the Cochrane review, which focused on 
the initiation of CWF, meant that the large body of contemporary data on CWF was excluded. Contemporary studies of the effectiveness of water CWF are primarily cross-sectional surveillance surveys in populations with established CWF programmes, where the use of fluoride toothpaste is ubiquitous. Reviews of such contemporary studies have reported substantial caries reductions in both children and adults who reside in fluoridated areas, compared to those in nonfluoridated areas (Griffin et al. 2007; Rugg-Gunn and Do 2012). A Cochrane review of the effectiveness of fluoride toothpaste also found an additional caries-preventive benefit when $\mathrm{F}$ toothpaste was used in areas with fluoridated water (Marinho et al. 2003).

Since its introduction in the mid-20th century, concerns have been expressed about the possible health effects of CWF. Several recent comprehensive reviews on the impact of fluoridated water on human health have been published (Scientific Committee on Health and Environmental Risks (SCHER) 2011; Royal Society of New Zealand \& Office of the Prime Minister's Chief Scientific Advisor 2014; Sutton et al. 2015; National Health and Medical Research Council (NHMRC 2016)). No reliable evidence for any adverse health effects associated with the use of fluoridated water at the low levels used in CWF were found by any of these reviews. One review also considered the environmental impact of artificially fluoridated water and concluded that exposure of environmental organisms to the levels of fluoride used for fluoridation of drinking water was not expected to lead to unacceptable risks to the environment (Scientific Committee on Health and Environmental Risks (SCHER) 2011).

Dental fluorosis at the lower levels (Dean's Index) is the only unwanted effect that is definitively associated with CWF. The Cochrane review of water fluoridation estimated a prevalence of $12 \%$ for fluorosis of aesthetic concern at water fluoride levels of $0.7 \mathrm{mg} / \mathrm{L}$ (Iheozor-Ejiofor et al. 2015).

Bottled drinking water is extensively used in many countries, including those with CWF, where it may displace the consumption of fluoridated tap water. Bottled water, if optimally fluoridated, could offer an additional option for population caries prevention. However, further research on the role of fluoride-containing bottled waters, dental caries and fluorosis is needed.

\section{Recommendation}

The EAPD reaffirms its support for the use of community water fluoridation as a safe, effective, relevant and costsaving public health measure for the prevention and control of dental caries. The Academy recognises that CWF alone is not a panacea but should be seen as an important element in a multi-faceted approach to caries prevention and control, which includes oral health promotion and access to affordable care.

The Academy recognises the need for ongoing population surveillance of the dental and health effects of fluoridated water to assure its continued safety, effectiveness and relevance.

Acknowledgements The European Academy of Paediatric Dentistry wishes to thank Professor Jack Toumba and Dr Nick A. Lygidakis (Workshop and Report Coordinators), for organising the Fluoride Workshop in Athens, Greece, November 16-17, 2018, that has enabled the updating of the EAPD Fluoride Guidelines. Special thanks should be attributed to those who took part in the Workshop and to the speakers in the scientific sessions, who all contributed their valuable knowledge leading to the development of these guidelines.

Workshop groups moderators and participants:

Fluoride Toothpaste: Moderator: Svante Twetman (Denmark). Participants: Dominique Declerck (Belgium), Norbert Kramer (Germany), Nick Lygidakis (Greece), Ulrich Schiffner (Germany), Jack Toumba (UK).

Fluoride Gels, Rinses and Varnishes: Moderator: Christian Splieth (Germany). Participants: Sotiria Gizani (Greece), Rita Cauwels (Belgium), William Papaioannou (Greece).

Fluoridated milk and salt, Fluoride tablets/lozenges and drops: Moderator: Cor van Loveren (The Netherlands). Participants: Elias Berdouses (Greece), Olga Cortes (Spain), Betul Kargul (Turkey), Katerina Kavvadia (Greece).

Water Fluoridation: Moderator: Carmel Parnell (Ireland). Participants: Mairead Harding (Ireland), Vassiliki Topitsoglou (Greece).

Fluorides and erosion: Adrian Lussi (Switzerland).

\section{Compliance with ethical standards}

Conflict of interest All authors declare that they have no conflict of interest.

Research involving human participants and/or animals The manuscript is a review/guideline article and hence does not involve human or animal participants.

Informed consent Informed consents are not required as the manuscript is a guideline/review paper not involving human or animal participants.

Open Access This article is distributed under the terms of the Creative Commons Attribution 4.0 International License (http://creativeco mmons.org/licenses/by/4.0/), which permits unrestricted use, distribution, and reproduction in any medium, provided you give appropriate credit to the original author(s) and the source, provide a link to the Creative Commons license, and indicate if changes were made.

\section{References}

Bian JY, Wang WH, Wang WJ, Rong WS, Lo ECM. Effect of fluoridated milk on caries in primary teeth: 21 -month results. Commun Dent Oral Epidemiol. 2003;31:241-5.

British Fluoridation Society. One in a million: The extent of water fluoridation. 2012. https://www.bfsweb.org/one-in-a-million. Accessed 16 Dec 2018. 
Burt BA. Prevention policies in the light of the changed distribution of dental caries. Acta Odontol Scand. 2008;195:7-63.

Buzalaf MA, Pessan JP, Honorio HM, ten Cate JM. Mechanisms of action of fluoride for caries control. Monogr Oral Sci. 2011;22:97-114.

Cagetti MG, Campus G, Milia E, Lingström P. A systematic review on fluoridated food in caries prevention. Acta Odontol Scand. 2013;71(3-4):381-7. https://doi.org/10.3109/00016 357.2012.690447.

Centers For Disease Control And Prevention. Community Water Fluoridation - Water Fluoridation Basics. CDC. 2016. https:// www.cdc.gov/fluoridation/basics/index.htm. Accessed 2 Dec 2018.

Crystal YO, Marghalani AA, Ureles SD, et al. Use of silver diamine fluoride for dental caries management in children and adolescents, including those with special health care needs. Pediatr Dent. 2017;39(5):E135-45.

da Silva AM, Hegde S, Akudo Nwagbara B, et al. Community-based population-level interventions for promoting child oral health. Cochrane Database Syst Rev. 2016;15(9):CD009837.

DenBesten PK. Biological mechanisms of dental fluorosis relevant to the use of fluoride supplements. Community Dent Oral Epidemiol. 1999;27:41-7.

Dos Santos APP, deOliveira BH, Nadanovsky P. A systematic review of the effects of supervised tooth brushing on caries incidence in children and adolescents. Int J Paediatr Dent. 2018;28:3-11.

EAPD, Toumba KJ, Lygidakis N, Oulis C, et al. Guidelines on the use of fluoride in children: an EAPD policy document. Eur Arch Paed Dent. 2009;10:129-35.

Espelid I. Systemic fluoride supplements-milk, salt and tablets. A literature review. Eur Arch Paediatr Dent. 2008;10(3):149-56.

Fabruccini A, Alves LS, Alvarez L, et al. Comparative effectiveness of water and salt community-based fluoridation methods in preventing dental caries among schoolchildren. Commun Dent Oral Epidemiol. 2016;44:577-85.

Featherstone JD. Prevention and reversal of dental caries: role of low level fluoride. Commun Dent Oral Epidemiol. 1999;27:31-40.

Fejerskov O. Changing paradigms in concepts on dental caries: consequences for oral health care. Caries Res. 2004;38:182-91.

Fejerskov O, Thylstrup A, Larsen MJ. Clinical and structural features and possible pathogenic mechanisms of dental fluorosis. Scand J Dent Res. 1977;85(7):510-34.

Fejerskov O, Thylstrup A, Larsen MJ. Rational use of fluorides in caries prevention. A concept based on possible cariostatic mechanisms. Acta Odontol Scand. 1981;39(4):241-9.

Gao S, Zhao I, Hiraishi N, et al. Clinical trials of silver di-amine fluoride in arresting caries among children: a systematic review. JDR Clin Transl Res. 2016;1(3):201-10.

Gao SS, Duangthip D, Wong MCM, Lo ECM, Chu CH. Randomized trial of silver nitrate with sodium fluoride for caries arrest. JDR Clin Trans Res. 2019;4(2):126-34. https://doi. org/10.1177/2380084418818482 (Epub 2019 Feb 15).

Griffin SO, Regnier E, Griffin PM, Huntley V. Effectiveness of fluoride in preventing caries in adults. J Dent Res. 2007;86:410-5.

Guyatt GH, Oxman AD, Kunz R, Falck-Ytter Y, Vist GE, Liberati A, Schünemann HJ, GRADE Working Group. Rating quality of evidence and strength of recommendations: going from evidence to recommendations. BMJ. 2008;336:1049-51.

Hong L, Levy SM, Warren JJ, et al. Fluoride intake levels in relation to fluorosis development in permanent maxillary central incisors and first molars. Caries Res. 2006;40(6):494-500.

Iheozor-Ejiofor Z, Worthington HV, Walsh T et al. Water fluoridation for the prevention of dental caries. Cochrane Database Syst Rev. 2015. https://doi.org/10.1002/14651858.CD010856.pub2.

Ismail AI, Bandekar RR. Fluoride supplements and fluorosis: a metaanalysis. Commun Dent Oral Epidemiol. 1999;27:48-56.
Jordan RA, Schulte A, Bockelbrink AC, et al. Caries-preventive effect of salt fluoridation in preschool children in The Gambia: a prospective, controlled, interventional study. Caries Res. 2017;51:596-604. https://doi.org/10.1159/000479892.

Jürgensen N, Petersen PE. Promoting oral health of children through schools: results from a WHO global survey 2012. Commun Dental Health. 2013;30:204-18.

Kassebaum NJ, Smith AGC, Bernabe E, et al. Global, regional, and national prevalence, incidence, and disability-adjusted life years for oral conditions for 195 Countries, 1990-2015: a systematic analysis for the global burden of diseases, injuries, and risk factors. J Dent Res. 2017;96:380-7.

Ketley CE, West JL, Lennon MA. The use of school milk as a vehicle for fluoride in Knowsley, UK; an evaluation of effectiveness. Commun Dent Health. 2003;20:83-8.

Levy SM, Kiritsy MC, Warren JJ. Sources of fluoride intake in children. J Public Health Dent. 1995;55:39-52.

Marinho VC. Cochrane reviews of randomized trials of fluoride therapies for preventing dental caries. Eur Arch Paediatr Dent. 2009;10:183-91.

Marinho VC, Higgins JP, Sheiham A, Logan S. Fluoride toothpastes for preventing dental caries in children and adolescents. Cochrane Database Syst Rev. 2003. https://doi. org/10.1002/14651858.CD002278.

Marinho VC, Worthington HV, Walsh T, Chong LY. Fluoride gels for preventing dental caries in children and adolescents. Cochrane Database Syst Rev. 2015. https://doi.org/10.1002/14651858. CD002280.pub2.

Marinho VC, Balshem H, Helfand M. GRADE guidelines: 3. Rating the quality of evidence. J Clin Epidemiol. 2011;64(4):401-6. https ://doi.org/10.1016/j.jclinepi.2010.07.015.

Marinho VC, Worthington HV, Walsh T, Clarkson JE. Fluoride varnishes for preventing dental caries in children and adolescents. Cochrane Database Syst Rev. 2013. https://doi.org/10.1002/14651 858.CD002279.pub2.

Marinho VC, Worthington Chong LY, Worthington HV, Walsh T. Fluoride mouth rinses for preventing dental caries in children and adolescents. Cochrane Database Syst Rev. 2016;7:CD002284. https ://doi.org/10.1002/14651858.cd002284.pub2.

Mejàre I. Current guidance for fluoride intake: is it appropriate? Adv Dent Res. 2018;29:167-76.

Mejàre IA, Klingberg G, Mowafi FK, et al. A systematic map of systematic reviews in pediatric dentistry-what do we really know? PLoS ONE. 2015;10(2):e0117537.

National Health And Medical Research Council (NHMRC), A. Health Effects of Water Fluoridation: Evidence Evaluation Report [Online]. Sydney. 2016. https://nhmrc.gov.au/about-us/ publications/water-fluoridation-dental-and-other-human-healt houtcomes\#block-views-block-file-attachments-content-block-1. Accessed 9 Dec 2018.

Network Scottish Intercollegiate Guidelines. Sign 50: A guideline developer's handbook. Scotland: Scottish Intercollegiate Guidelines Network; 2008.

O'Mullane DM, Baez RJ, Jones S, et al. Fluoride and oral health. Commun Dental Health. 2016;33:69-99.

Oulis CJ, Raadal I, Martens L. Guidelines on the use of fluoride in children: an EAPD policy document. Eur J Paediatr Dent. 2000;1:7-12.

Pollick H. Salt fluoridation: a review. CDA J. 2013;41:395-404.

Poulsen S. Fluoride containing gels, mouthrinses and varnishes. An update of efficacy. Eur Arch Paediatr Dent. 2009;10(3):157-61.

Pretty IA. High fluoride concentration toothpastes for children and adolescents. Caries Res. 2016;50(Suppl 1):9-14.

Public Health Agency Of Canada. Canada. 2016. https://www.canad a.ca/content/dam/canada/health-canada/migration/publications/ 
healthy-living-viesaine/cpho-ocdo-final-position-statement-eng. pdf. Accessed 16 Dec 2018.

Ran T, Chattopadhyay SK. Economic evaluation of community water fluoridation: a community guide systematic review. Am J Prev Med. 2016;50:790-6.

Rolla G, Ogaard B, Cruz RDA. Clinical effect and mechanism of cariostatic action of fluoride- containing toothpastes: a review. Int Dent J. 1991;41:171-4.

Royal Society of New Zealand and Office Of The Prime Minister's Chief Scientific Advisor. Health effects of water fluoridation: A review of the scientific evidence. 2014. http://www.pmcsa.org.nz/ wp-content/uploads/Health-effects-of-water-fluoridation-Aug20 14.pdf. Accessed 09 Dec 2018.

Rugg-Gunn AJ, Do L. Effectiveness of water fluoridation in caries prevention. Commun Dent Oral Epidemiol. 2012;40(Suppl 2):55-64.

Ryan R, Hill S. How to GRADE the quality of the evidence. Cochrane Consumers and Communication Group. 2016. http://cccrg.cochr ane.org/author-resources. Version 3.0 December 2016.

Schwendicke F, Splieth CH, Thomson WM, et al. Cost-effectiveness of caries-preventive fluoride varnish applications in clinic settings among patients of low, moderate and high risk. Commun Dent Oral Epidemiol. 2018;46(1):8-16. https://doi.org/10.1111/ cdoe. 12320

Scientific Committee on Health And Environmental Risks (SCHER). Critical review of any new evidence on the hazard profile, health effects, and human exposure to fluoride and the fluoridating agents of drinking water. Brussels: European Commission. 2011. https ://ec.europa.eu/health/scientific_committees/environmental_risks /docs/scher_o_139.pdf. Accessed 16 Dec 2018.

Scottish Intercollegiate Guidelines Network. Prevention and management of dental decay in the pre-school child. A national clinical guideline. No. 83. In, 2005: 44.

Slayton RL, Urquhart O, Araujo MWB, et al. Evidence-based clinical practice guideline on nonrestorative treatments for carious lesions: a report from the American Dental Association. J Am Dent Assoc. 2018;149(10):837-49.

Stecksén-Blicks C, Sjöström I, Twetman S. Effect of longterm consumption of milk supplemented with probiotic lactobacilli and fluoride on dental caries and general health in preschool children: a cluster-randomized study. Caries Res. 2009;43:374-81.

Sutton M, Kiersey R, Farragher L, Long J. Health effects of water fluoridation - an evidence review. Ireland: Health Res Board; 2015.

Takahashi R, Ota E, Hoshi K et al. Fluoride supplementation (with tablets, drops, lozenges or chewing gum) in pregnant women for preventing dental caries in the primary teeth of their children. Cochrane Database of Systematic Reviews 2017, 10, CD011850. https://doi.org/10.1002/14651858.cd011850.pub2.

Tirupathi S, Svsg N, Rajasekhar S, Nuvvula S. Comparative cariostatic efficacy of a novel Nano-silver fluoride varnish with $38 \%$ silver diamine fluoride varnish a double-blind randomized clinical trial. J Clin Exp Dent. 2019;11(2):e105-12. https://doi.org/10.4317/ jced.54995.

Tomasin L, Pusinanti L, Zerman N. The role of fluoride tablets in the prophylaxis of dental caries. A literature review. Ann di Stomatol. 2015;VI(1):1-5.

Tubert-Jeannin S, Auclair C, Amsallem E et al. Fluoride supplements (tablets, drops, lozenges or chewing gums) for preventing dental caries in children. Cochrane Database Syst Rev. 2011. https://doi. org/10.1002/14651858.CD007592.pub2.

Twetman S. Caries prevention with fluoride toothpaste in children: an update. Eur Arch Paediatr Dent. 2009;10:162-7.

Twetman S, Axelsson S, Dahlgren H, et al. Caries-preventive effect of fluoride toothpaste: a systematic review. Acta Odontol Scand. 2003;61:347-55.

Twetman S, Keller MK. Fluoride rinses, gels and foams: an update of controlled clinical trials. Caries Res. 2016;50(Suppl 1):38-44. https://doi.org/10.1159/000439180.

Urquhart O, Tampi MP, Pilcher L, et al. Non-restorative treatments for caries: systematic review and network meta-analysis. J Dent Res. 2019;98(1):14-26.

Walsh T, Worthington HV, Glenny AM et al. Fluoride toothpastes of different concentrations for preventing dental caries in children and adolescents. Cochrane Database Syst Rev 2019, 3:CD007868. https://doi.org/10.1002/14651858.cd007868.pub3.

Wennhall I, Hajem S, Ilros S, et al. Fluoridated salt for caries prevention and control-a 2-year field study in a disadvantaged community. Int J Paediatr Dent. 2014;24:161-7.

Wong MC, Glenny AM, Tsang BW, et al. Topical fluoride as a cause of dental fluorosis in children. Cochrane Database Syst Rev. 2010 Jan 20;(1):CD007693. https://doi.org/10.1002/14651858.cd007 693.pub2.

Wong MC, Clarkson J, Glenny AM, et al. Cochrane reviews on the benefits/risks of fluoride toothpastes. J Dent Res. 2011;90:573-9.

Wright JT, Hanson N, Ristic H, et al. Fluoride toothpaste efficacy and safety in children younger than 6 years: a systematic review. J Am Dent Assoc. 2014;145:182-9.

Yengopal V, Chikte UM, Mickenautsch S, Oliveira LB, Bhayat A. Salt fluoridation: a meta-analysis of its efficacy for caries prevention. SADJ. 2010;65:60-7.

Yeung CA, Chong LY, Glenny AM. Fluoridated milk for preventing dental caries. Cochrane Database Syst Rev. 2015 Sep 3;(9):CD003876. https://doi.org/10.1002/14651858.cd003876.

Publisher's Note Springer Nature remains neutral with regard to jurisdictional claims in published maps and institutional affiliations. 